\title{
Editorial on the revised European Training Charter for Clinical Radiology
}

\author{
European Society of Radiology (ESR)
}

Received: 17 November 2011 / Accepted: 22 November 2011 /Published online: 15 January 2012

(C) European Society of Radiology 2012

\begin{abstract}
This short editorial introduces the revised European Training Charter for Clinical Radiology. The revised Charter reiterates the principle of a five-year basic training composed of an initial threeyear training followed by Subspecialist Interest training during the fourth and fifth years.

Key Points

- This European Training Charter for Clinical Radiology will harmonise training across Europe.

- The principle of a 5-year training programme is reinforced.

- The Charter provides flexibility with regards to subspecialist interests.
\end{abstract}

Keywords Training · Clinical radiology · General training · Subspecialist interest training

A revision of the European Training Charter for Clinical Radiology was completed and presented in pdf format on the ESR website in February 2011 [1]. The document represents a revision of the original Training Charter. (This original training charter was completed by the European Association of Radiology in association with the radiology section of UEMS in 2003. As with that document, the present Training Charter has also been ratified by the UEMS Section Radiology. This collaboration ensures that a single educational voice for European radiology is presented, and that maximum cooperative agreement is attained).

The exponential growth in training requirements for diagnostic radiology which has resulted from the explosion in

European Society of Radiology (ESR) $(\square)$

Neutorgasse 9/2,

1010 Vienna, Austria

e-mail: communications@myESR.org new imaging technologies is emphasised in the decision by the ESR Executive Council that the present revision should be made available in pdf format and subject to regular updating and revision. The electronic format is available for print out from the ESR website (www.myesr.org/trainingcharter), and hard copy versions can be obtained from the ESR Office on request.

The Training Charter is now divided into three components. The first section deals with general principles of radiological education including duration of training, structures of training, facility requirements of training, and the incorporation of continuous learning and competence during training.

The revised Charter reiterates the principle of a 5-year basic training period as being the appropriate duration of training required by a general radiologist for independent clinical practice. It recommends an initial 3-year period during which the trainee should be exposed to all the major subspecialties in radiology. Subspecialist interest training should be obtained in at least two areas during the fourth and fifth years. During the fourth and fifth years, at least $50 \%$ of trainee time should remain devoted to achieving further competence in general radiology. The document envisages subspecialty interest training at this level as being quite distinct from subsequent subspecialty fellowship training, where a more total immersion in the relevant subspecialty would take place. It is also envisaged that general radiology may be included in the subspecialty interest options in its own right during the fourth and fifth years of training.

Recommended rotational programmes through the various subspecialties are also outlined, as are study facility requirements, access to e-learning, competence through log book appraisals, mentoring principles and the integration of radiology training within lifelong learning. 
New subjects which have been incorporated into Part I of the Charter include formalised training in communication, medico-legal and management skills.

Part II of the document is devoted to listing the knowledge requirements in the various subspecialties of radiology to be achieved during years $1-3$. These basic requirements are outlined and have been expanded to include newer technologies including hybrid imaging and molecular imaging and newer areas of interventional radiology competence required of the general radiologist. Curriculum additions on emergency and oncologic radiology are being elaborated in association with the newly established European Society of Emergency Radiology (ESER) and the European Society of Oncologic Imaging (ESOI) for early incorporation in the revised curriculum.

Part III of the document includes submissions by the subspecialty societies affiliated with the European Society of Radiology for subspecialty interest level knowledge requirements. Reflecting the individual approaches of the differing subspecialty societies, this section of the curriculum is characterised by a degree of heterogeneity. An initiative to standardise this section of the curriculum has commenced, and it is hoped that a more standardised format will be available for future editions.

The provision of an updated curriculum represents a significant step forward in the construction of a matrix of educational initiatives aimed at standardisation of educational structures in radiology throughout Europe. This matrix includes all educational initiatives of ESR including e-learning, ECR courses and the various electronic and hard copy publications of the Society.

By applying standardised ESR terminology to all of these initiatives, a uniform and easily cross-referenced platform is being created by ESR. The integration of all ESR educational endeavours has been accelerated and focussed by the development of a European Diploma in Radiology, where knowledge requirements are based on the updated curriculum. The curriculum also provides assistance to those negotiating improved standards of radiology training in various countries and serves as a reference for accreditation programmes, which have become a priority for the ESR under a reinvigorated European Training Assessment Programme which is run also in association with UEMS.

Acknowledgements This editorial was kindly prepared by Éamann Breatnach, chairman of the ESR Education Committee, and was approved by the ESR Executive Council in October 2011.

\section{References}

1. European Society of Radiology (2011) Revised European training charter for clinical radiology. http://www.myesr.org/html/img/pool/ European_Training_Charter_current_version_February_2011.pdf 